\begin{tabular}{c} 
International Journal of Engineering \& Technology, $7(1)(2018)$ 157-164 \\
International Journal of Engineering \& Technology \\
SPC \\
Website: $\begin{array}{c}\text { www.sciencepubco.com/index.php/IJET } \\
\text { doi: } 10.14419 / \text { ijet. } v 7 i 1.9090 \\
\text { Research paper }\end{array}$ \\
\hline
\end{tabular}

\title{
Experimental and numerical investigations on the thermal performance of hemp such a bio-sourced insulation material: application to a Moroccan Mediterranean climate
}

\author{
Maryam Dlimi *, Omar Iken, Rachid Agounoun, Amine Zoubir, Khalid Sbai \\ The Laboratory of Studying Advanced Materials and Applications (LEM2A),Moulay Ismail University, Meknes-Morocco \\ *Corresponding author E-mail:dlimi.maryam@gmail.com
}

\begin{abstract}
Thermal performance of hemp concrete and hemp wool such as ecological insulation was evaluated for the city of Meknes in Morocco, in comparison with polystyrene which is an organic insulation material. The study was done in three sections. First, a thermo-physical properties characterization was done using the EI700 device. Then, the study was done on a concrete wall subjected to periodic outdoor conditions. The three insulation materials are used and the effects of thickness, location and partitioning on the time lag and decrement factor were investigated. Finally, heating and cooling loads of a whole building with the use of six different walls configurations are calculated using TRNSYS software. Throughout the whole study, results show that hemp wool presented the best thermal performance, and the evaluation of its use such us an insulation material in Morocco and especially in Meknes was investigated.
\end{abstract}

Keywords:Decrement Factor; Heating \& Cooling Loads; Hemp; Morocco; Thermal Insulation; Time Lag.

\section{Introduction}

In the international context of the limitation of greenhouse gas emissions (GHG) and the predictable exhaustion of the world fossil energy resources, searches are led in order to meet the needs of the building field which represents the largest energyconsuming sector in the world.

In morocco, this sector is responsible of $25 \%$ of energy consumption with 18\% for residential building [1]. From 2000 to 2010, the energy consumption due to air conditioning has increased significantly, and the energy consumption of heating has almost doubled. Therefore, the heating and air conditioning of buildings are among the areas where the most important savings can be achieved. In this context, the improvement of the energy performances of buildings has constituted one of the main structural measures of energy efficiency in Morocco, and thus, a thermal regulation has been adopted in November 2014 [1] with the main purpose of improving the thermal performances of the buildings envelopes. Thermal insulation leads to operational energy savings [2], contributing at the same time to the reduction of environmental pollution due to current energy production systems, which consume high amounts of fossil fuels which pollutes the environment.

Polystyrene is among the materials which are widely used for thermal insulation; its use in construction allows to significantly reducing the operational energy requirements [3].

But from an ecological point of view, thermal insulating materials such as polystyrene are highly energy consuming.

In this context, new regulations for thermal insulation in the building sector lead researchers to investigate new insulation materials to create energy-saving systems. This research quickly turned to the use of bio-sourced insulation materials.
The use of the hemp as an ecological material is a way to ensure a sustainable development and to reduce the impact of the building energy demand.

Hemp wool derived from natural fibers, and hemp concrete produced from a mixture of hemp shives and lime, can be used as insulation materials [4].

Today, the political strategy of Morocco takes into account the consideration of the sustainable development and the impact of the energy demand in building. Moreover, the hemp is a part of the natural heritage of this country and offer incredible possibilities of exploitation.

This work focuses on a comparison study between thermal performance of polystyrene EPS, hemp concrete and hemp wool. Firstly, we started by the characterization of the thermo-physical properties of each insulating material using the boxes method. Then, parameters such as insulation thickness and location are evaluated in order to investigate their effect on time lag and decrement factor concerning an insulated concrete wall. Finally, using TRNSYS software, heating and air conditioning loads are calculated throughout a year for an insulated room located at the city of Meknes. Based on obtained results, we evaluated the thermal performance of hemp concrete and hemp wool and compared it with EPS.

\section{Thermal properties characterization: boxes method (EI700 device)}

The thermo-physical characterization of the three materials (Fig.1) has been done using the EI700 Device, a unit developed by The Laboratory of Thermal and Solar Studies of Claude Bernard University in Lyon. This device contains two boxes, the first one for 
the thermal conductivity measurement and the second one for the thermal diffusivity measurement (Fig.2). The method used is called the boxes method [5].

(A)

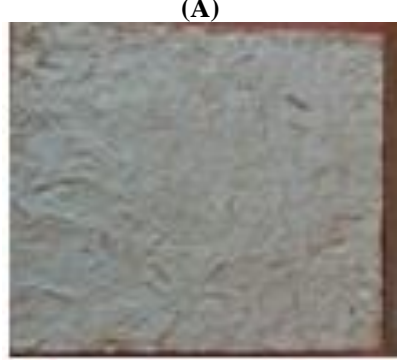

(B)

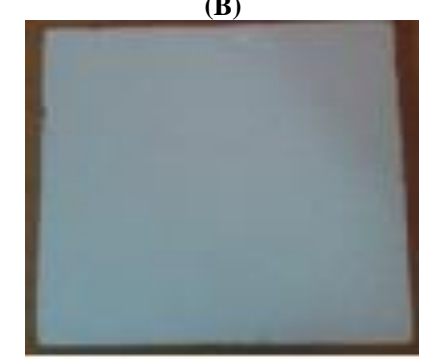

(C)

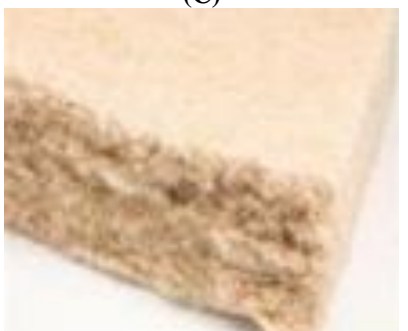

Fig. 1: Insulation Material's Samples: (A) Hemp Concrete, (B) Polystyrene, (C) Hemp Wool.

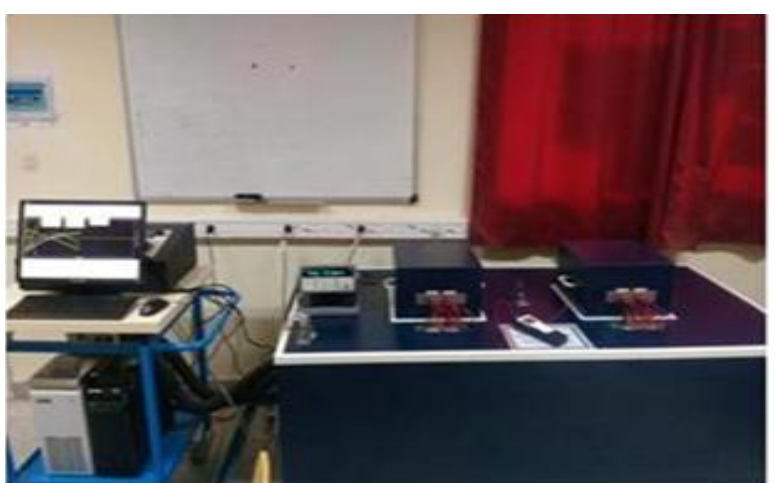

Fig. 2: EI700 Device "Boxes Method".

\subsection{Thermal conductivity measurement}

The experimental measurement of the thermal conductivity consists in imposing a permanent unidirectional heat flux through the studied sample placed in the first box B1 (Fig1). This one is placed between the cold isothermal capacityof the device and the heat source with a constant heat flux. A rheostat is used in order to adjust the temperature $T_{B 1}$ inside the box B1 at a level slightly higher than the ambient temperature $\left(T_{B 1}-T_{a m b}<0.1^{\circ} \mathrm{C}\right)$. The steady state is reached after approximately three hours, i.e. when the values of temperatures remain constant for a long time, the temperature gradient on both sides in the middle surfaces of the sample, the ambient temperature and the heating voltage are recorded.

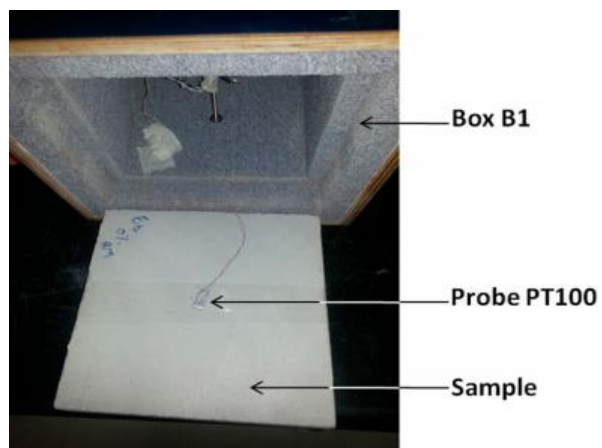

Fig.3: The Box B1 Used for Thermal Conductivity Measurement
Thermal conductivity is deduced from the thermal balance:

$\varphi_{j}=\varphi_{l}+\varphi_{c}$ With:

- $\varphi_{j}=V^{2} / R$ is the Joule Effect produced by the heating source,

- $\varphi_{l}=\beta\left(T_{B 1}-T_{a m b}\right)$ is the global heat losses through the box $\mathrm{B} 1$,

- $\varphi_{c}=\frac{\lambda S}{e}\left(T_{H}-T_{C}\right)$ is the conductive heat flux through the sample.

Equation (1) is used to deduce the experimental value of the thermal conductivity $\lambda_{\exp }$ :

$$
\lambda_{\exp }=\frac{e}{S\left(T_{H}-T_{C}\right)}\left[\varphi-\beta\left(T_{B 1}-T_{a m b}\right)\right]
$$

\subsection{Thermal diffusivity measurement}

For the thermal diffusivity measurement [6], the sample is placed into the second box B2 (Fig.2) and heated from the bottom using incandescent lamps with $1000 \mathrm{~W}$ radiative power. After few seconds of heating, temperatures values of the sample's top face are recorded. The times corresponding to the $1 / 3,1 / 2,2 / 3$, and $5 / 6$ fractions of the maximum value of the recorded temperatures are then identified. The experimental thermal diffusivity of the material is then deduced by averaging the three values calculated by the following expressions:

$\left\{\begin{array}{l}\alpha_{1}=\frac{e^{2}}{t_{5 / 6}^{2}}\left[1,15 \cdot t_{5 / 6}-1,25 \cdot t_{2 / 3}\right] \\ \alpha_{2}=\frac{e^{2}}{t_{5 / 6}^{2}}\left[1,15 \cdot t_{5 / 6}-1,25 \cdot t_{1 / 2}\right] \\ \alpha_{3}=\frac{e^{2}}{t_{5 / 6}^{2}}\left[1,15 \cdot t_{5 / 6}-1,25 \cdot t_{1 / 3}\right]\end{array}\right\}$

$\alpha_{\exp }=\frac{\alpha_{1}+\alpha_{2}+\alpha_{3}}{3}$

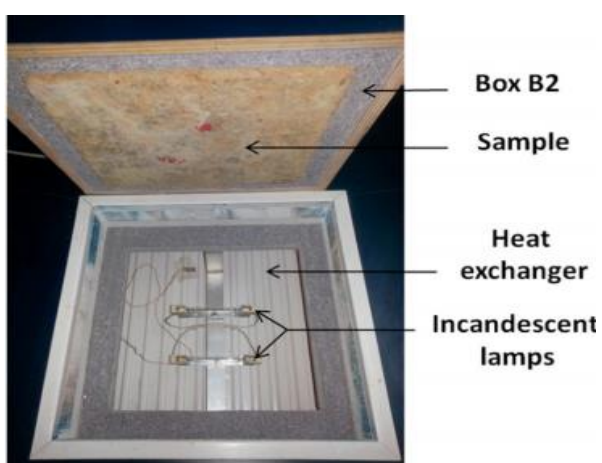

Fig. 4: View of the Box B2 Used for Thermal Diffusivity Measurement.

\subsection{Density and specific heat}

After experimental measurement of the thermal conductivity and thermal diffusivity of the samples, their density and specific heat $C p$ are calculated using the following equations:

$\rho=\frac{m_{\text {Sample }}}{V_{\text {Sample }}}$ 


$$
C p_{\exp }=\frac{\lambda_{\exp }}{\rho_{\exp } \cdot \alpha_{\exp }}
$$

The experimental thermo-physical properties are presented in table 1.

Table 1: Measured Thermal Properties of the Insulating Materials

\begin{tabular}{llll}
\hline $\begin{array}{l}\text { Insulation } \\
\text { material }\end{array}$ & $\lambda(\mathrm{W} / \mathrm{m} \cdot \mathrm{K})$ & $\rho\left(\mathrm{kg} / \mathrm{m}^{3}\right)$ & $\mathrm{C}_{\mathrm{p}}(\mathrm{J} / \mathrm{kg} \cdot \mathrm{K})$ \\
\hline Hemp concrete & 0.11 & 420 & 1300 \\
Polystyrene & 0.041 & 25 & 1500 \\
Hemp wool & 0.040 & 35 & 1000 \\
\hline
\end{tabular}

These values are close to that founded in the literature [7], [8], [9].

\section{Thermal behavior study of a simple wall subjected to periodic outdoor temperature}

\subsection{Theoretical investigation of time lag and decrement factor}

To evaluate the dynamic thermal performance of a wall and to determine the heat storage capabilities of any material, it is important to study two physical parameters that demonstrate the thermal response of building.

During the propagation of the heat flux from the outer wall surface to the inner one, its amplitude decreases depending on the thermophysical properties of materials (Fig.4). When the flux reaches the inner wall surface, it will have an amplitude which is considerably smaller than the amplitude of the external wall surface [10], [11], [12]. The decrement factor (f) is determined by the following equation:

$f=\frac{T_{s i}^{\max }-T_{s i}^{\min }}{T_{s e}^{\max }-T_{s e}^{\min }}$

Where $T_{s i}$ and $T_{s e}$ are the inner and the outer surface temperatures respectively.

The time that the heat wave takes to propagate from the outer surface to the inner surface of a wall is called time lag $\varphi$ and is defined by:

$$
\varphi=\left\{\begin{array}{l}
t_{T_{s i}^{\max }}>t_{T_{s e}^{\max }} \Rightarrow t_{T_{s i}^{\max }}-t_{T_{s e}^{\max }} \\
t_{T_{s i}^{\max }}<t_{T_{s e}^{\max }} \Rightarrow t_{T_{s i}^{\max }}-t_{T_{s e}^{\max }}+P \\
t_{T_{s i}^{\max }}=t_{T_{s e}^{\max }} \Rightarrow P
\end{array}\right\}
$$

Where $\mathrm{P}$ (hours) is the propagation wave period.

\subsection{Governing equation and boundary conditions}

The heat transfer in the wall is assumed to be one-dimensional. The transient heat conduction problem expressed by Equation (8) has been solved by using an implicit finite difference scheme for a multilayer wall [13], [14].

$\rho C \frac{\partial T}{\partial t}=\lambda \frac{\partial^{2} T}{\partial x}$

The boundary conditions are:

$$
-\lambda \frac{\partial T}{\partial x}=h_{e}\left(T_{s a}-T_{s e}\right)(x=0)
$$

$-\lambda \frac{\partial T}{\partial x}=h_{i}\left(T_{s i}-T_{i}\right)(x=l)$

Where $h_{e}$ and $h_{i}$ are the exterior and the interior surface convective heat transfer coefficients of the wall respectively. $T_{s a}, T_{s e}$, $T_{s i}, T_{i}$ are the sol-air temperature, the external surface temperature of the wall, the internal surface temperature of the wall and the indoor air temperature respectively.

The sol-air temperature $T_{s a}$ includes the effects of the solar radiation combined with outside air temperature and changes periodically. This temperature is assumed to show sinusoidal variations during a 24-h period. Since time lag and decrement factor are dependent on only wall materiel, not on the weather data, a very general equation for sol-air temperature is taken as follows:

$T_{s a}=\frac{T_{\max }-T_{\min }}{2} \sin \left(\frac{2 \pi t}{P}-\frac{\pi}{2}\right)+\frac{T_{\max }-T_{\min }}{2}+T_{\min }$

For our case, the sol-air temperature chosen corresponds to the coldest day in Meknes and is defined as:

$T_{s a}=5,5 \times \sin \left(\frac{2 \pi t}{24}-\frac{\pi}{2}\right)+10,5, P=24 h, h_{e}=25 \mathrm{~W} / \mathrm{m}^{2} \mathrm{~K}$,

$h_{i}=7.69 \mathrm{~W} / \mathrm{m}^{2} \mathrm{~K}, T_{i}=19^{\circ} \mathrm{C}$,

And the steady-state solution of the problem is taken as an initial condition at $(t=0)$.

In order to investigate the thermal performance of hemp concrete and hemp wool as new bio-sourced insulating materials in Morocco, a comparative study with the expanded polystyrene EPS is done. The effect of thickness, location and partitioning on the time $\operatorname{lag} \varphi$ and the decrement factor $\mathrm{f}$ are discussed.

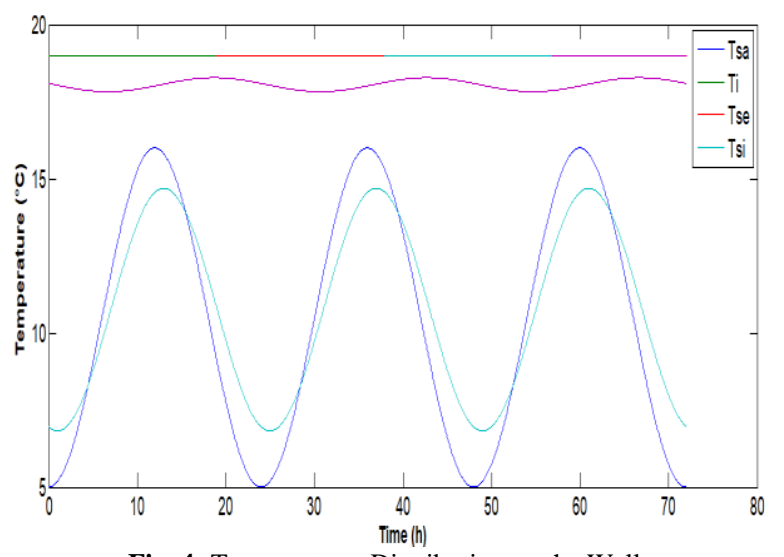

Fig. 4: Temperatures Distribution on the Wall.

\subsection{Thickness effect on the time lag and the decrement factor}

The study is done for a vertical concrete wall incorporating a thermal insulation layer with different thicknesses.

Thus, the examined wall consists of two layers, as follows:

- Massive layer (C): normal concrete layer with a constant thickness, $\mathrm{e}=20 \mathrm{~cm}$.

- Insulation layer (I): insulation materials chosen are hemp concrete, hemp wool and EPS. The insulation thickness is assumed to vary from $\mathrm{e}=2 \mathrm{~cm}$ to $14 \mathrm{~cm}$, by steps of $2 \mathrm{~cm}$.

The variations of the decrement factor $\mathrm{f}$ and the time lag $\varphi$ with the increase of thickness for the different studied insulation layers are depicted in (Fig.5) and (Fig.6).

We can see that the increase in the insulation layer thickness leads to a decrease of the decrement factor and an increase of the time lag. 
Comparing the three insulation materials performance, it is clearly shown that the concrete wall insulated with hemp wool and the one insulatedwith EPS represent approximately the same decrement factor and the same time lag. Forboth configurations,we can see that exceeding the value of $\mathrm{e}=10 \mathrm{~cm}$, time lag remains practically constant (Fig.6) and the effect of increasing the thickness is less pronounced on the decrement factor variation (Fig.5).

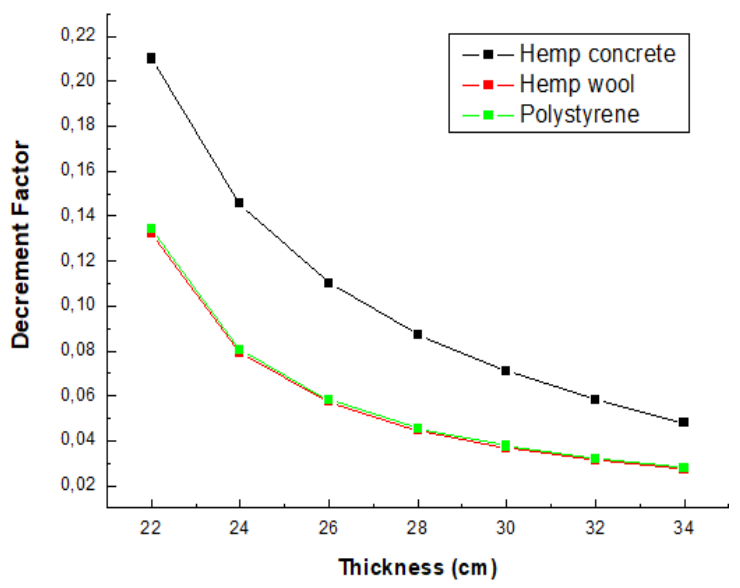

Fig. 5: Effect of the Thickness Variation on Decrement Factor.

Concerning the hemp concrete, its represents a decrement factor higher than hemp wool and EPS (Fig.5).This is due to its thermal conductivity which is relatively higher than that of hemp wool and EPS. Nevertheless, because of its heat capacity that exceed 700 (J/kg.K) [10], [15], [16], the resulted decrement factor allows the hemp concrete to perform as well as hemp wool and EPS but with thicknesses higher than $10 \mathrm{~cm}$. As for the time lag, it keeps increasing with the increase of the insulation thickness (Fig.6).

These results explain that the increase of the insulation thickness improves the thermal behaviour of a multilayer wall.

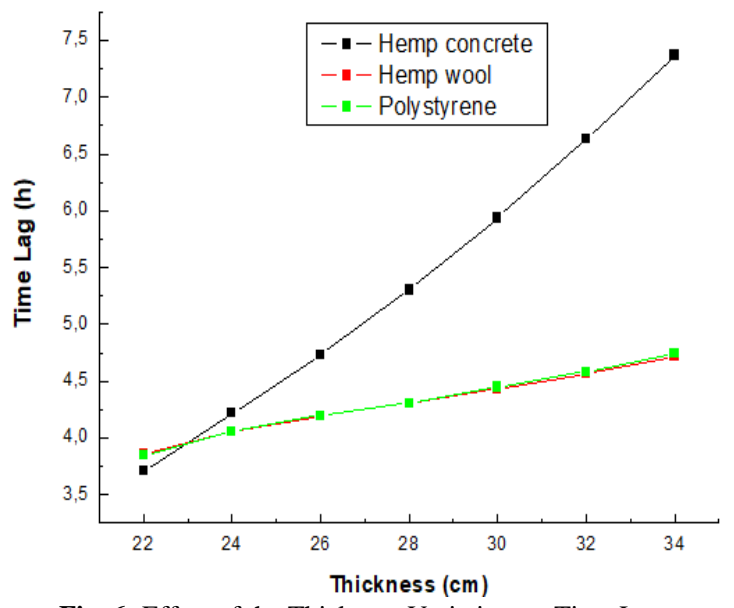

Fig. 6: Effect of the Thickness Variation on Time Lag.

\subsection{Insulation location effect on time lag and decrement factor}

Time lag and decrement factor of a concrete wall with an internal insulation layer are compared to those calculated when the insulation layer is located on the outside.

Fig.7, 8, 9, 10, 11 and 12 show the important effect of changing the location of the insulation material from inside to outside.

With the use of hemp wool and EPS, the time lag results show an increase of 2 hours for all the thicknesses studied (Fig.10) and (Fig.12). For those higher than $10 \mathrm{~cm}$, the time lag remains constant on 8 hours which is the value recommended by literature for a performing external insulation [11].

When the hemp concrete is used as an external insulation layer (Fig.8), time lag increases by 1 hour comparing to the internal insulation results and still increases with the increase of the thicknessesand reaching 11 hours for $\mathrm{e}=14 \mathrm{~cm}$.

Concerning the decrement factor, results obtained for the external insulation are practically 2 times lower than those obtained in the case of an internal insulation, and that for the three insulation materials studied (Fig.7), (Fig.9) and (Fig.11).

The comparison between the two configurations shows that data reported in literature on the layer order influence [17], [18] are easy explained within our study. It indicates how arranging an insulating layer on the external side of a multilayer wall (IC configuration) is always more effective than starting with a massive layer (CI configuration).

It is also apparent that order is more important than thickness and that using a thin insulating layer in IC configuration is more effective than using a two times larger insulating layer in CI configuration.

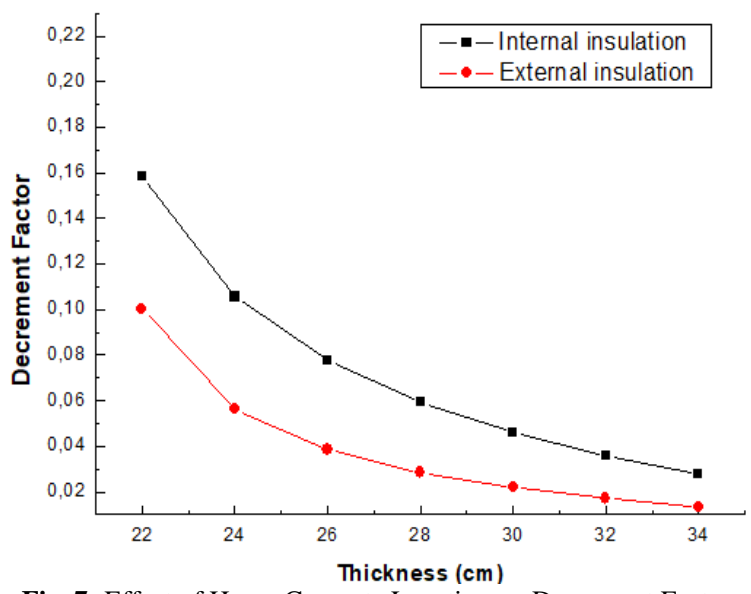

Fig. 7: Effect of Hemp Concrete Location on Decrement Factor.

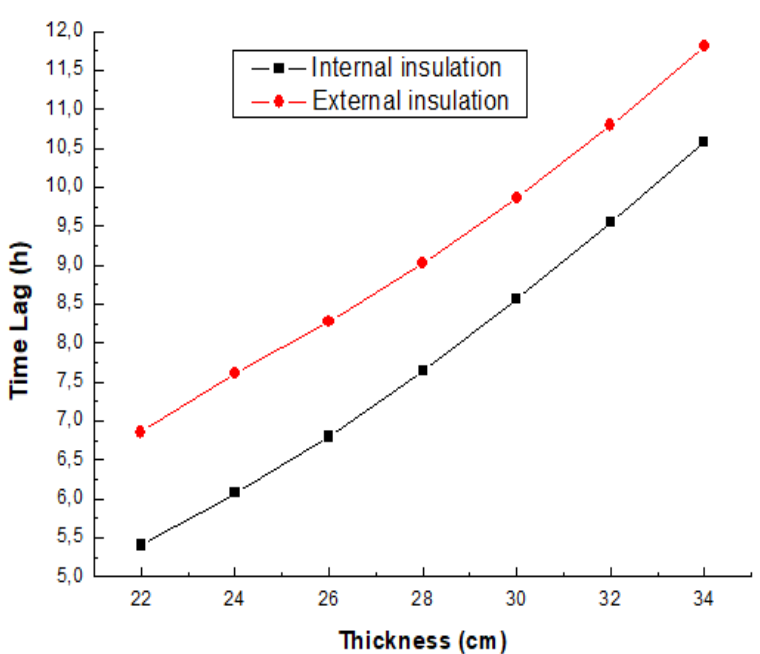

Fig. 8: Effect of Hemp Concrete Location on Time Lag.

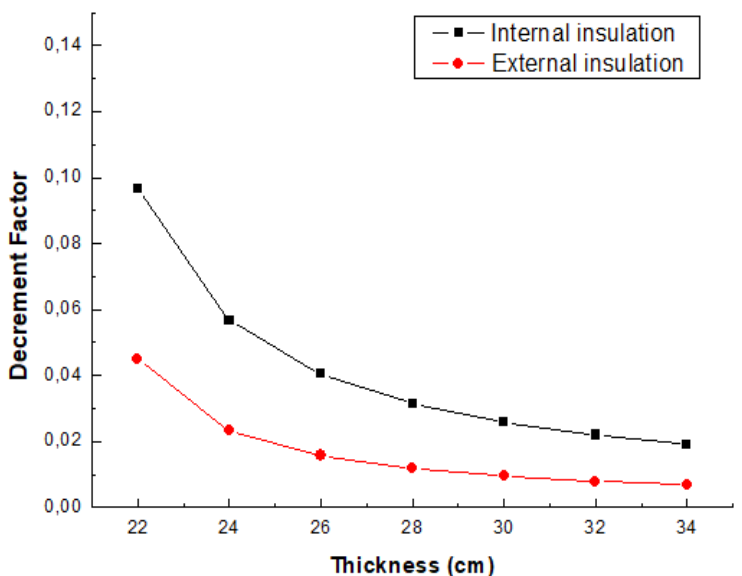

Fig. 9: Effect of Hemp Wool Location on Decrement Factor. 


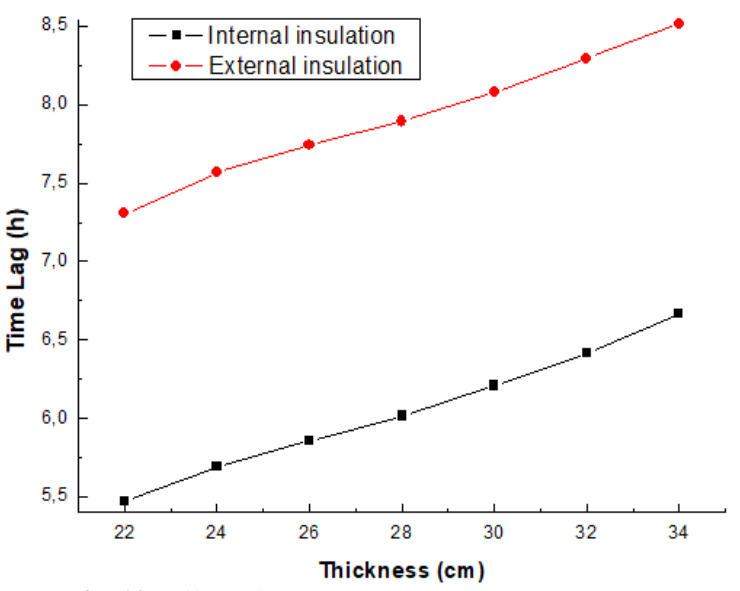

Fig. 10: Effect of Hemp Wool Location on Time Lag.

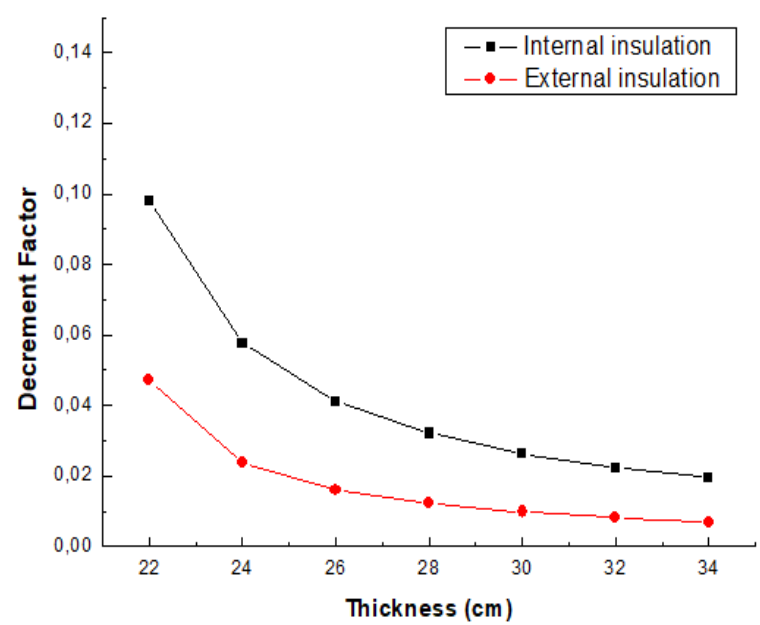

Fig. 11: Effect of EPS Location on Decrement Factor.

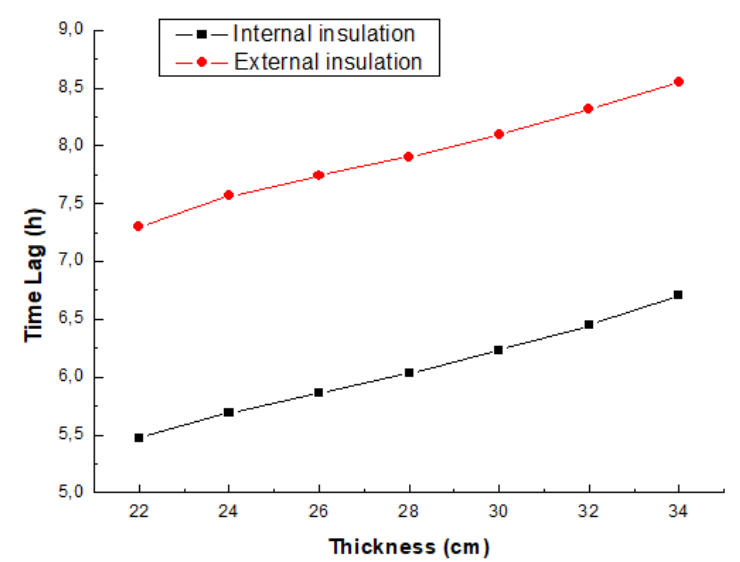

Fig. 12: Effect of EPS Location on Time Lag.

\subsection{Layer partitioning effect on time lag and decrement factor}

While keeping constant the total thickness of the multilayer wall, recent works [19], [20] had shown that increasing the partitioning of layers, could improve the insulation capabilities of a wall. In this section, we are considering the two basic bilayers IC and CI configurations and their thermal behavior is compared to the one of four wall configurations: afirst three layer wall with two equal concrete layers and a single intermediate insulating layer denoted by CIC, a second three layer wall with the insulating layer divided into two equal parts denotedby ICI, two four layers wall configurations denotedby CICI andICIC respectively, where each layer is split into two equal parts.

\subsubsection{Effect of wall configuration on decrement factor}

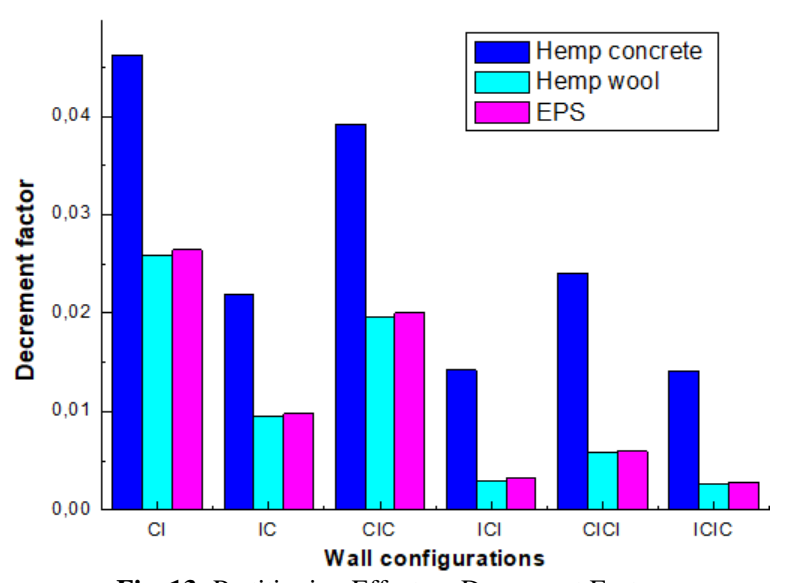

Fig. 13: Partitioning Effect on Decrement Factor.

Values of decrement factor are presented in (Fig.13) for different wall configurations. As we see, f varies considerably among wall configurations. When the concrete layer is placed from the outside and the configuration wall changes from two, to three, then to four layers respectively (CI, CIC and CICI), the largest $f$ pertains to the $\mathrm{CI}$ configuration, then it is reduced by 0.006 for the CIC configuration and by 0.01 for the CICI one. When the insulation layer is placed from the outside, and the configuration wall changes from two to three layers (IC and ICI), the $\mathrm{f}$ is also reduced by 0.006 . This diminution is less pronounced when passing from three layers to four layers (ICI and ICIC) and the decrement factor remains practically constant.

The above results for layer partitioning effects on time lag and decrement factor are similar to those obtained analytically by Gori [19] using the heat transfer matrix approach under steady periodic conditions.

\subsubsection{Effect of wall configuration on time lag}

Values of time lag for all configurations are presented in (Fig.14). It is quite interesting to note the huge effect that wall configuration has on time lag. The shortest time lag pertains to the CI configuration with a single layer of insulation placed on inside, it varies between 6 and 8,5 hours for the three insulation materials studied.

By placing the insulation layer on the outside (IC configuration), time lag increases by nearly 2 hours. For the three layers wall, passing from the CIC configuration to the ICI one gives an increase in time lag of 20 minutes when the hemp concrete is used, and 1,5 hours when hemp wool and EPS are used. Significant increase in time lag is further achieved by moving to the next category of wall with two equal layers of concrete and two equal layers of insulation. The ICIC configuration gives the longest time lag of over $11 \mathrm{~h}$, which is about twice of the CI configuration time lag.

For the CICI configuration, the use of hemp wool and EPS gives the same time lag of about 8,5 hours, while 9 hours are reached with the use of hemp concrete.

These differences in time lag are attributed to pure effect of redistribution of layers under dynamic conditions. 


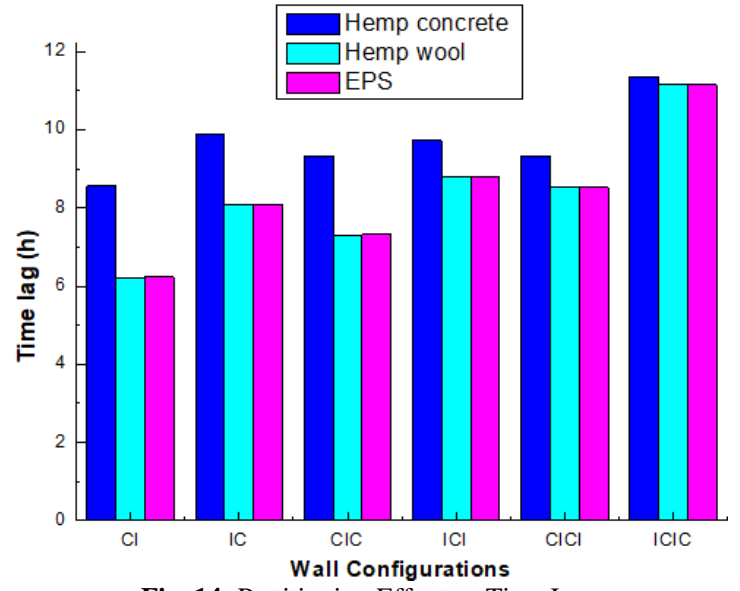

Fig. 14: Partitioning Effect on Time Lag.

\section{Dynamic thermal performance of a whole building}

The considered building is located in Meknes, Morocco $\left(33.9^{\circ} \mathrm{N}\right.$; $5.5^{\circ} \mathrm{W}$ and $549 \mathrm{~m}$ of altitude). It's a room with a floor area of 80 $\mathrm{m}^{2}$ and a total volume of $240 \mathrm{~m}^{3}$. All the walls constituting the room are made with a $20 \mathrm{~cm}$ total thickness of concrete, $10 \mathrm{~cm}$ total thickness of insulation material and $2 \mathrm{~cm}$ of mortar from inside and outside.

A transient mono-zone thermal simulation model is applied for modeling the building [21]. Simulations were conducted with all the previous configurations, using each time one of the insulation materials studied. Comparisons of the cooling and heating loads will allow the evaluation of the thermal performance of each material and each configuration.

The simulations consist of the hourly calculation of the free running air temperature inside the room. These calculations are done using TRNSYS software [22] with the following hypotheses:

- No internal heat generation (the house is unoccupied),

- Initial temperature and humidity are taken at $20^{\circ} \mathrm{C}$ and $50 \%$ respectively,

- The effect of thermal bridges and shading is not taken into account,

- No infiltrations,

- Solar absorptivity of the walls and the roof is 0.6,

- Standard heat transfer coefficients are considered.

According to the Moroccan standard NM ISO 7730 RTCM [23], set temperatures of 19 and $26{ }^{\circ} \mathrm{C}$ are taken for heating and air conditioning respectively.

Results of the whole-building dynamic modeling showed that walls containing massive internal layers IC, ICIC and CIC have the best annual thermal performance (Fig.15), (Fig.16) and (Fig.17).

The lowest annual heating and cooling loads are obtained for the IC configuration, where the entire massive layer is concentrated on the inside. CI configuration, with all the insulation material located on the inside, generates the largest energy demand. For the ICI and CICI wall configurations, their energy demand falls between the energy demand for the CI configuration and the most efficient configurations, IC, ICIC and CIC.

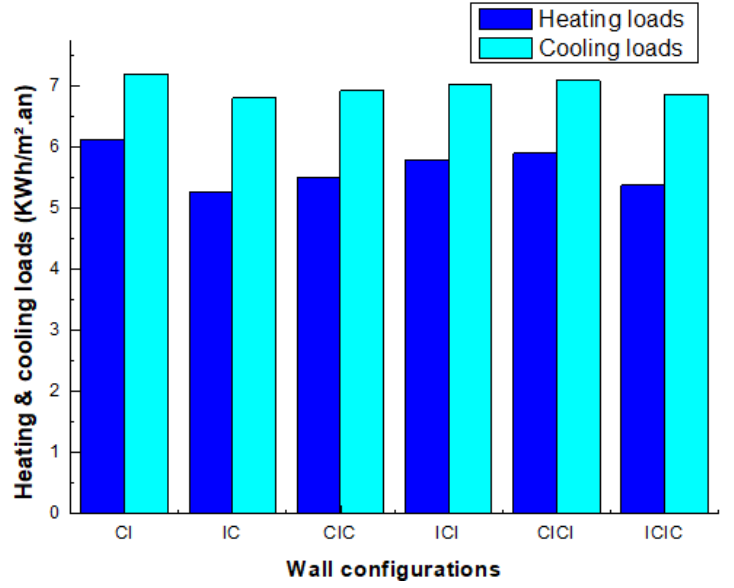

Fig. 15: Heating \& Cooling Loads for an Insulated Building with Hemp Concrete.

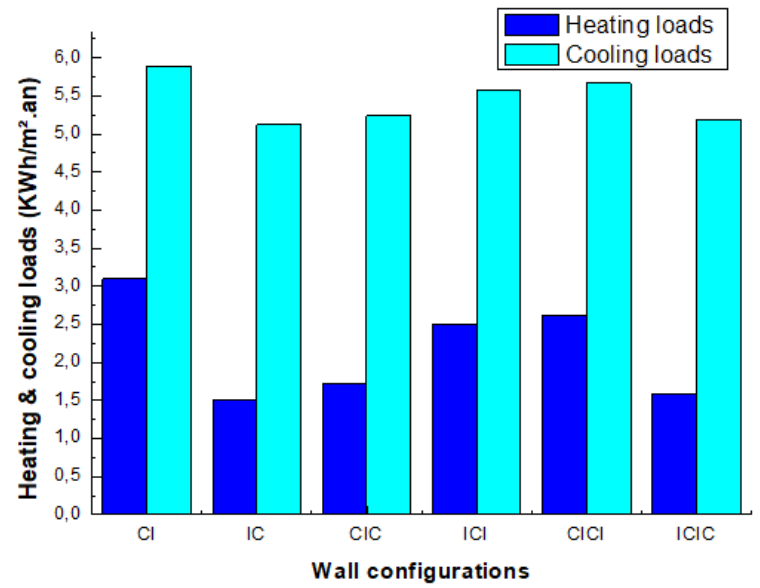

Fig. 16: Heating \& Cooling Loads for an Insulated Building with Hemp Wool.

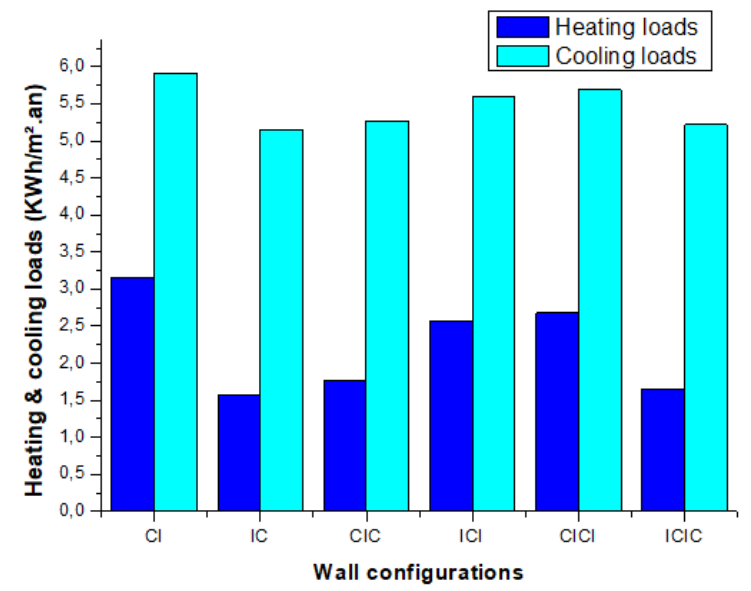

Fig. 17: Heating \& Cooling Loads for an Insulated Building with EPS.

With regard to energy savings, these data indicate that locating the insulation on the exterior of the walls is preferable.

Heating and cooling loads for the least efficient and the most efficient configurations were compared to that of a typical house in Meknes. Materials used in the construction of the external walls, roof and the ceiling [24], [25] are presented in table 2 . 
Table 2: Materials Used in the Reference House Construction

\begin{tabular}{lll}
\multicolumn{2}{c}{ Table 2: Materials Used in the Reference House Construction } \\
\hline \multirow{4}{*}{ External walls } & Material & Thickness $(\mathrm{cm})$ \\
& Plaster & 1,5 \\
& Hollow brick & 7 \\
& Air cavity & 10 \\
& Hollow brick & 7 \\
& Plaster & 1,5 \\
Roof & Ceramic tile & 2 \\
& Cement mortar & 5 \\
& Pre-stressed concrete & 4 \\
& Hourdis & 16 \\
Floor & Plaster & 1 \\
& Ceramic tile & 2 \\
& Cement mortar & 5 \\
\hline
\end{tabular}

We can notice that for the heating loads (Fig.18), when the hemp concrete is used, loads decrease by a percentage of $14 \%$ from CI to IC configurations. When hemp wool and EPS are used, this percentage increases to 45 and 50\% respectively. By comparing the heating loads of the reference house to that of the most efficient configuration, a reduction of 73 and $92 \%$ is observed when hemp concrete, hemp wool and EPS are used, respectively.

For the cooling loads (Fig.19), when the hemp concrete is used, they decrease by $5 \%$ from CI to IC configuration. When hemp wool and EPS are used, cooling loads are reduced by 13, 05 and $12,90 \%$ respectively. By comparing the cooling loads of the reference house to that of the most efficient configuration, a reduction of 78 and $83 \%$ is observed when hemp concrete, hemp wool and EPS are used, respectively.

For the city of Meknes, the energy demand concerning the heating is higher than the one concerning the air conditioning. This is due to the fact that this city is characterized by a moderate winter and a hot summer.

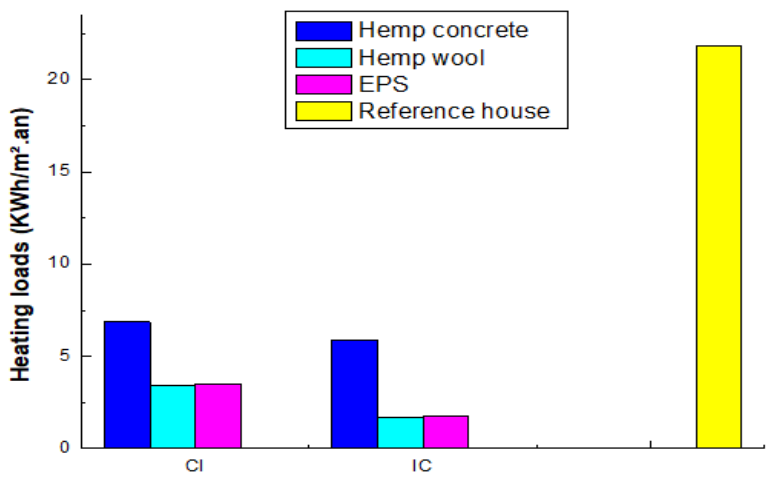

Wall configuration

Fig. 18: Heating Loads for the Least and the Most Efficient Configurations.

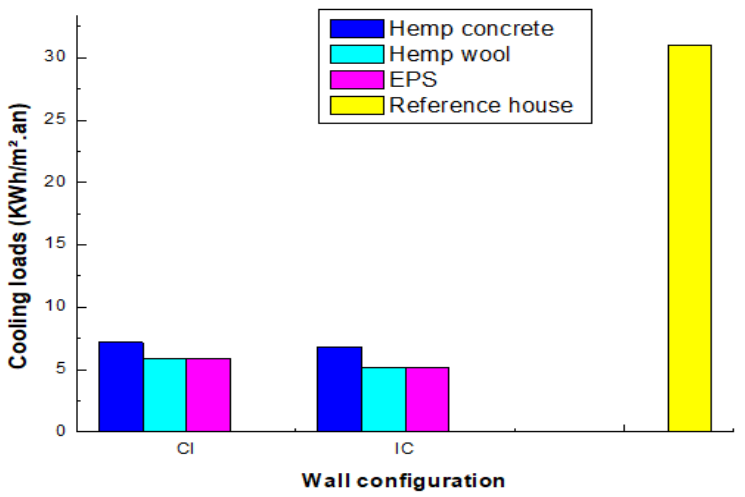

Fig. 19: Cooling Loads for the Least and the Most Efficient Configurations.

\section{Conclusion}

In this paper, our aim was to compare the insulation performance of hemp concrete and hemp wool with the performance of EPS for the city of Meknes in Morocco. We began by the characterization of the thermo-physical properties of the three insulation materials studied, then each material was associated to a $20 \mathrm{~cm}$ fixed thickness of a concrete wall, the thickness, location and partitioning effects on time lag and decrement factor were investigated.

Results show that the concrete walls insulated with hemp wool and EPS have practically the same thermal behavior with a slight superiority for the hemp wool insulation material. This is due to the fact that the two materials have the same lower thermal conductivity. The thermal behavior of the concrete wall insulated with hemp concrete is less efficient than the other concrete walls because of its relatively high thermal conductivity and heat capacity. The effect of layer partitioning on time lag, decrement factor, heating and cooling loads was investigated, and six configuration walls were studied (CI, IC, CIC, ICI, CICI, ICIC). Results show that partitioning has a huge effect on time lag and decrement factor. For the time lag, it increases from 6 hours obtained for the CI configuration to 11 hours obtained with the ICIC configuration which represent almost the double. Concerning the decrement factor, it decreases by $10,5 \%$ from CI to ICIC configuration. However, when the thermal performance of a whole building is studied, and regarding to heating and cooling loads, results show that the best performance is obtained when the total thickness of insulation is located on the outside.

The thermal performance of the three insulation materials was studied starting by the characterization of their thermal properties, going through evaluating their thermal behavior for a simple wall subjected to sinusoidal outdoor conditions, until their integration on a whole building. To conclude, throughout the whole study, hemp wool presented the best thermal performance, and the evaluation of its use such us an insulation material in Morocco and especially in Meknes was investigated.

\section{References}

[1] ADEREE, Les éléments techniques du projet de la réglementation thermique du bâtiment au Maroc, (2011).

[2] İ.Ayçam, M.Tuna, "Evaluation of Insulation Materials in the Context of Sustainability Criteria", Asian Transactions on Basic and Applied Sciences, 2013.

[3] A. Bojan., C. Aciu, "Optimal Technologies for External Thermal Insulation with Polystyrene Panels for Different Support Materials," Procedia Technology, 2015.

[4] E. Latif, S. Tucker, M.A. Ciupala, D.C. Wiyjeyesekera, D. Newport, "Hygric properties of five hemp bio-insulations with different compositions," Construction and Building Materials 66:702711,September 2014.https://doi.org/10.1016/j.conbuildmat.2014.06.021.

[5] M. Boumhaout, L. Boukhattem, F. AitNouh, H. Hamdi, B. Benhamou, "Energy efficiency in buildings: thermophysical characterization of building materials," Int. Renewable and Sustainable Energy Conf. IRSEC2013, (7-9 March 2013)Ouarzazate (Morocco).https://doi.org/10.1109/IRSEC.2013.6529675.

[6] M. Lachi, A. Degiovanni, "Influence de l'erreur de mesure de température de surface par thermocouples de contact sur la détermination de la diffusivité thermique par méthode « flash »", J. Phys. III France 2, (1992) 2247.https://doi.org/10.1051/jp3:1992244.

[7] K.S. Reddy, S. Jayachandran , "Investigations on design and construction of a square guarded hot plate (SGHP) apparatus for thermal conductivity measurement of insulation materials," International Journal of Thermal Sciences, Volume 120, (October 2017), pp.

136 147.https://doi.org/10.1016/i.ijthermalsci.2017.06.001

[8] P. Gong, G. Wang, M.P. Tran, P. Buahom, S. Zhai, G. Li, C.B. Park, "Advanced bimodal polystyrene/multi-walled carbon nanotube nanocomposite foams for thermal insulation," Carbon, Volume 120, (August 2017), pp. 1-10. https://doi.org/10.1016/i.carbon.2017.05.029.

[9] R. Bevan, T. Woolley, "Hemp lime construction: a guide to building with hemp lime composites," Bracknell: IHS BRE Press; 2008.

[10] H. Asan, "Numerical computation of time lag and decrement factors for different building materials", Building and Environment 41(2006), 615 620.https://doi.org/10.1016/j.buildenv.2005.02.020 
[11] K.J. Kontoleon, E.A. Eumorfopoulou, "The influence of wall orientation and exterior surface solar absorptivity on time lag and decrement factor in the Greek region", Renewable Energy 33 (2008), pp.1652-1664.https://doi.org/10.1016/j.renene.2007.09.008.

[12] C. Sun, S.Shu, G.Ding, X. Zhang, X.Hu, "Investigation of time lags and decrement factors for different building outside temperatures", Energy and Buildings 61 (2013), pp. 17.https://doi.org/10.1016/j.enbuild.2013.02.003.

[13] MN.Ozısık, "Finite Difference Methods in Heat Transfer", CRC Pres, 1994.

[14] B. Belhadj, M. Bederina, Z. Makhloufi, A. Goullieux, M. Quéneudec, "Study of the thermal performances of an exterior wall of barley strawsand concrete in an arid environment", Energy and Buildings $\quad 87, \quad$ (2015), pp. 175.https://doi.org/10.1016/j.enbuild.2014.11.034.

[15] X.Jin, X.Zhang, Y.Cao, G.Wang, "Thermal performance evaluation of the wall using heat flux time lag and decrement factor", Energy and Buildings 47, (2012) pp. 369374.https://doi.org/10.1016/j.enbuild.2011.12.010.

[16] C. Maalouf, A.D. Tran Le, L. Chahwane, M. Lachi, E. Wurtz, T.H Mai, "A study of the use of thermal inertia in simple layer walls and its application to the use of a vegetal fiber material in buildings", International Journal of Energy, Environment and Economics, January 2011

[17] S.A.Al-Sanea, M.F.Zedan, "Improving thermal performance of building walls by optimizing insulation layer distribution and thickness for same thermal mass", Appl. Energy 88 (2011), pp.31133124.https://doi.org/10.1016/j.apenergy.2011.02.036.

[18] D.E.M Bond, W.W.Clark, M. Kimber, "Configuring wall layers for improved insulation performance", Appl. Energy 112 (2013), pp.235-245.https://doi.org/10.1016/j.apenergy.2013.06.024

[19] P.Gori, C.Guattari, L.Evangelisti, F.Asdrubali, "Design criteria for improving insulation effectiveness of multilayer walls", International Journal of Heat and Mass Transfer 103 (2016), pp. 349359.https://doi.org/10.1016/j.ijheatmasstransfer.2016.07.077.

[20] E.Kossecka, J.Kosny, "Influence of insulation configuration on heating and cooling loads in a continuously used building", Energy and Buildings $34 \quad$ (2002) pp 331.https://doi.org/10.1016/S0378-7788(01)00121-9.

[21] Z.Romani, A.Draoui, F.Allard, "Metamodeling the heating and cooling energy needs and simultaneous building envelope optimization for low energy building design in Morocco", Energy and Buildings, Vol.102, (2015), pp. 139 148.https://doi.org/10.1016/j.enbuild.2015.04.014.

[22] S. Klein, et al., "A Transient System Simulation Program", Solar Energy Laboratory, University of Wisconsin-Madison, Madison, WI, USA, 2000

[23] Thermal Building Regulations in Morocco, ADEREE Morocco.

[24] B.Benhamou, A.Bennouna, "Energy Performances of a Passive Building inMarrakech:Parametric Study", Energy Procedia 42, ( 2013 ), pp. 624 632.https://doi.org/10.1016/j.egypro.2013.11.064

[25] R. Guechchati, M. A. Moussaoui, Ahm. Mezrhab, and Abd. Mezrhab, "Reducing Energy Consumption of Habitat Located in Eastern Region of Morocco", Applied Solar Energy, (2012), Vol. 48, No. 1, pp. 33-37.https://doi.org/10.3103/S0003701X12010069. 